\title{
PRESSURE AND TEMPERATURE ESTIMATES FOR SEVERAL EOCENE PLUTONS IN THE CASCADE FOOTHILLS AND EASTERN PUGET LOWLANDS OF WASHINGTON STATE: A RECORD OF EOCENE SYN-TECTONIC INTRUSION AND EOCENE TO PRESENT FAULTING
}

Jamie MacDonald', Joe Dragovich², Glenn Thompson ${ }^{3}$, Jeff Tepper, Kevin Wise ${ }^{1}$, Andy DuFrane ${ }^{5}$, and Megan Anderson ${ }^{6}$

${ }^{1}$ Florida Gulf Coast University, ${ }^{2}$ Associated Earth Sciences, ${ }^{3}$ Syracuse University, ${ }^{4}$ University of Puget Sound, ${ }^{5}$ University of Alberta, ${ }^{6}$ Washington Geological Survey
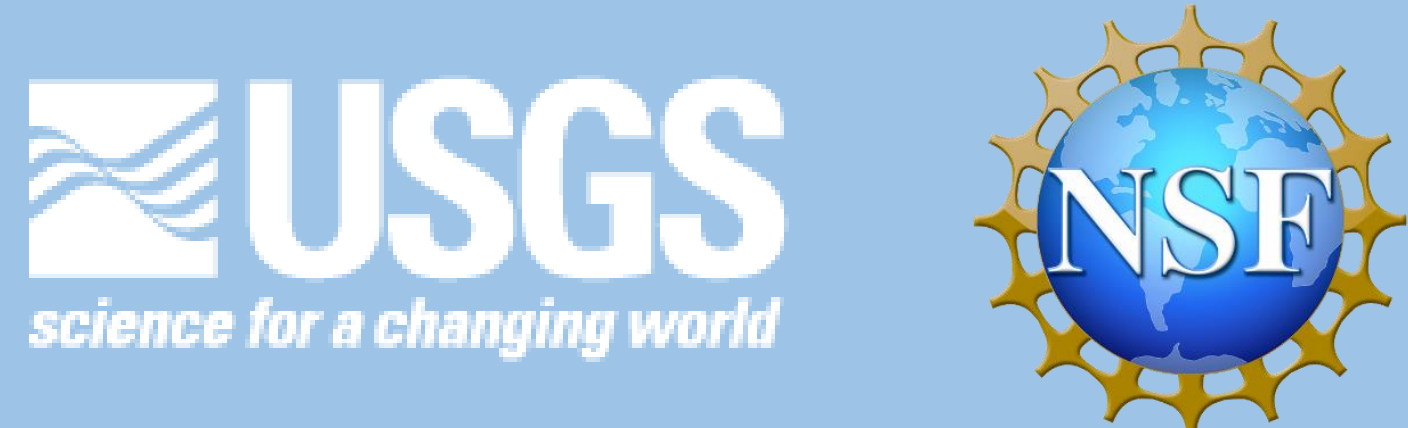


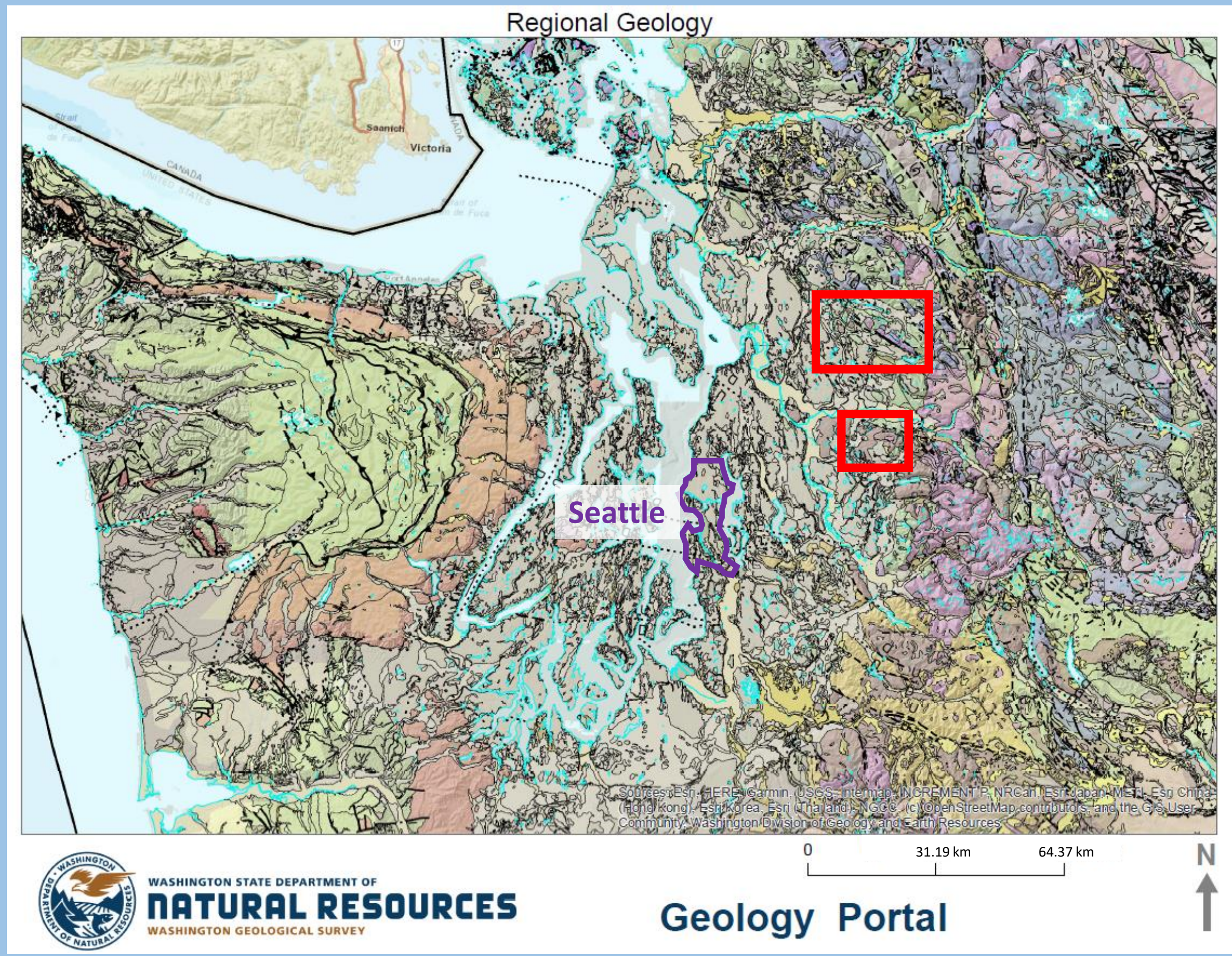

Regional Geology of Western Washington State.

Highlighted in the red boxes are the locations of several Eocene Plutons discussed in this talk.

The Youngs Creek intrusive complex is to the south, while the Bald Mt. pluton, Mt. Pilchuck stock, and Granite Falls stock are to the north 
Youngs Creek intrusive complex

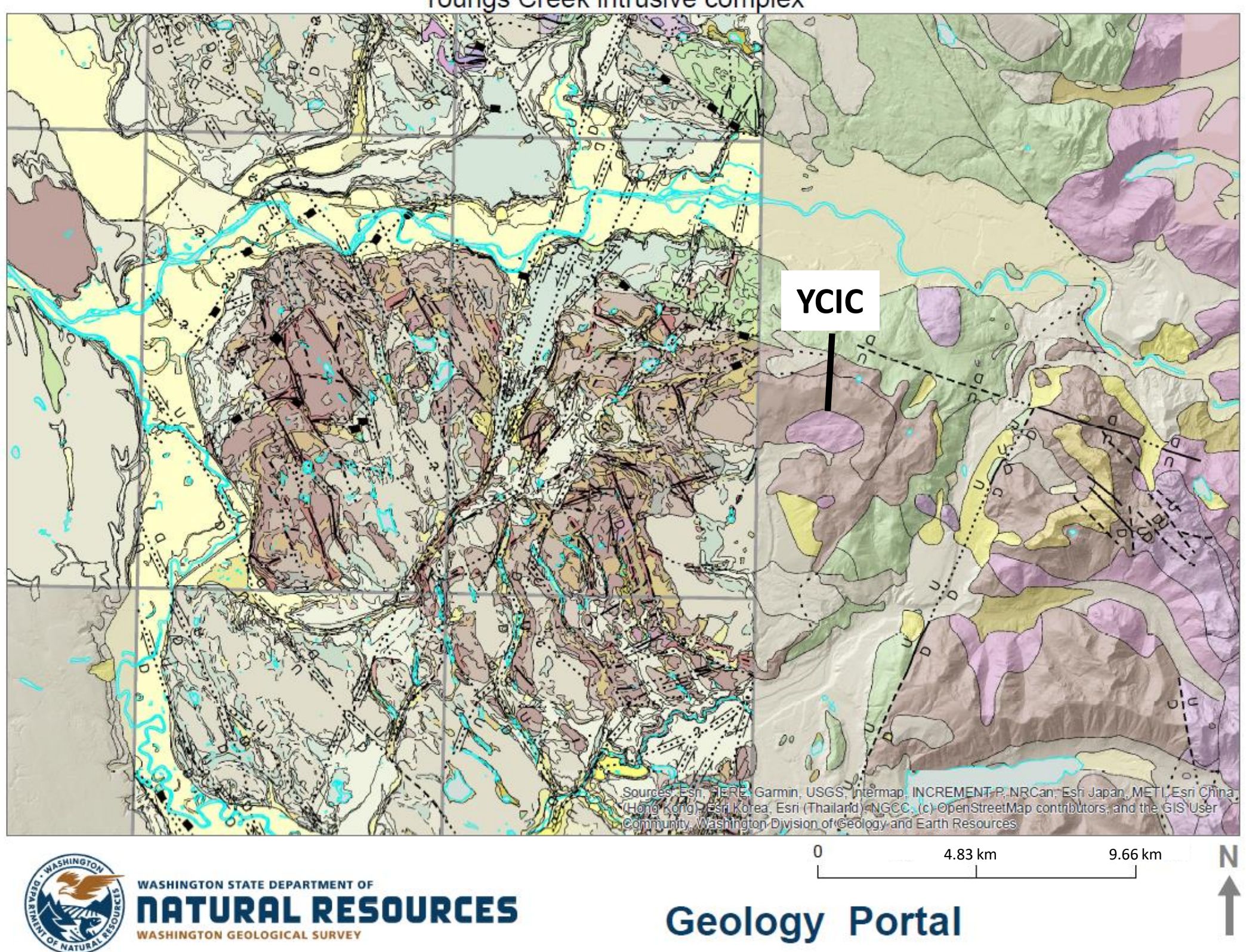

YCIC $=$ Youngs Creek intrusive complex.

The light brown rocks are the volcanic rocks of Mount Persis.

The other pink colored rocks to the east of the YCIC are the Oligocene Index batholith.

Dragovich et al. (2013) suggested, base primarily on age and location, the Youngs Creek intrusive complex was one of the magmatic sources of the volcanic rocks of Mount Persis. 


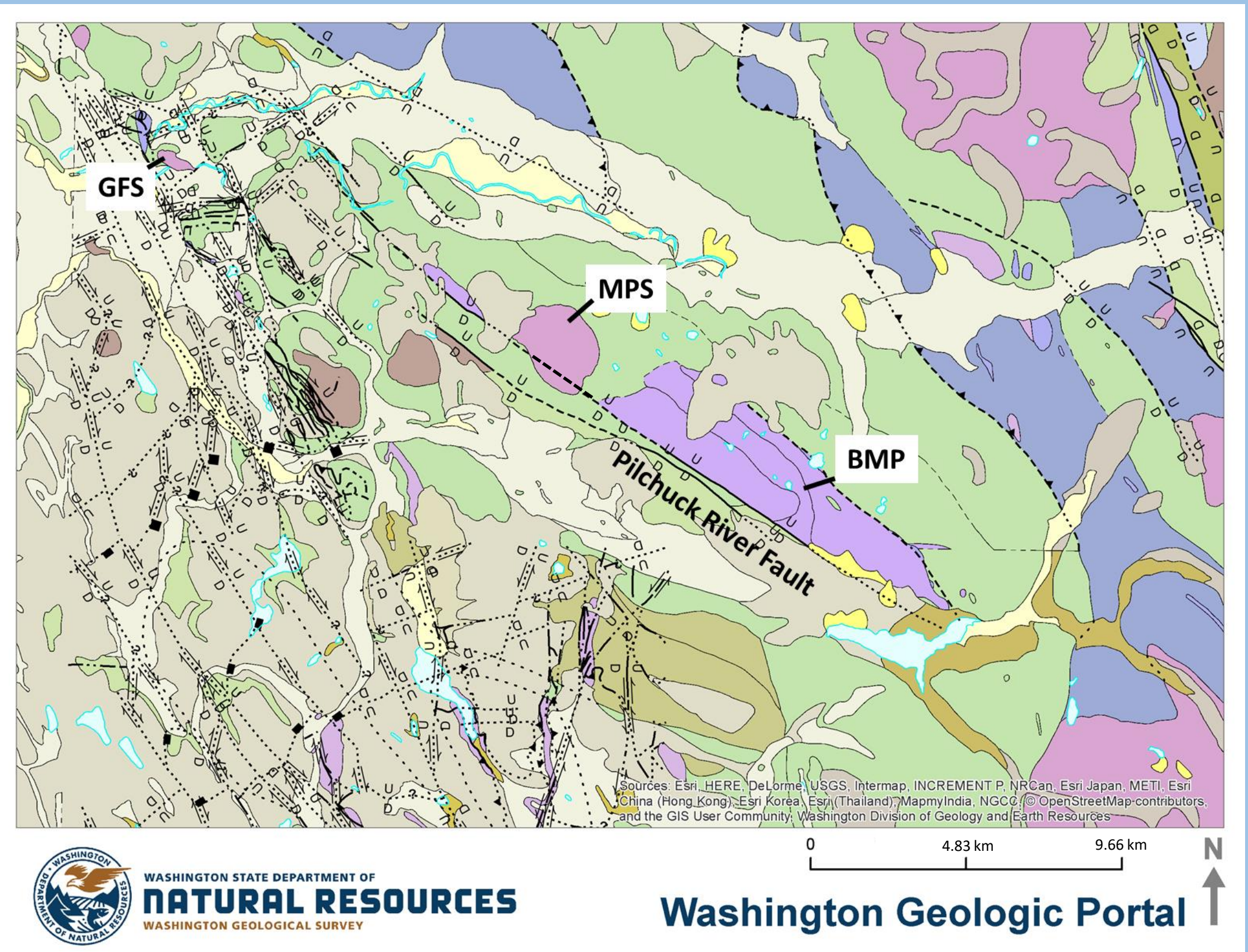

BMP = Bald Mountain pluton GFS = Granite Falls stock MPS = Mount Pilchuck stock

The pink rocks to the far east are, again, the Oligocene Index batholith.

The green rocks are both the eastern and western mélange belts.

Note the Pilchuck River Fault of Wiebe (1963) and Tabor et al. (2002). 


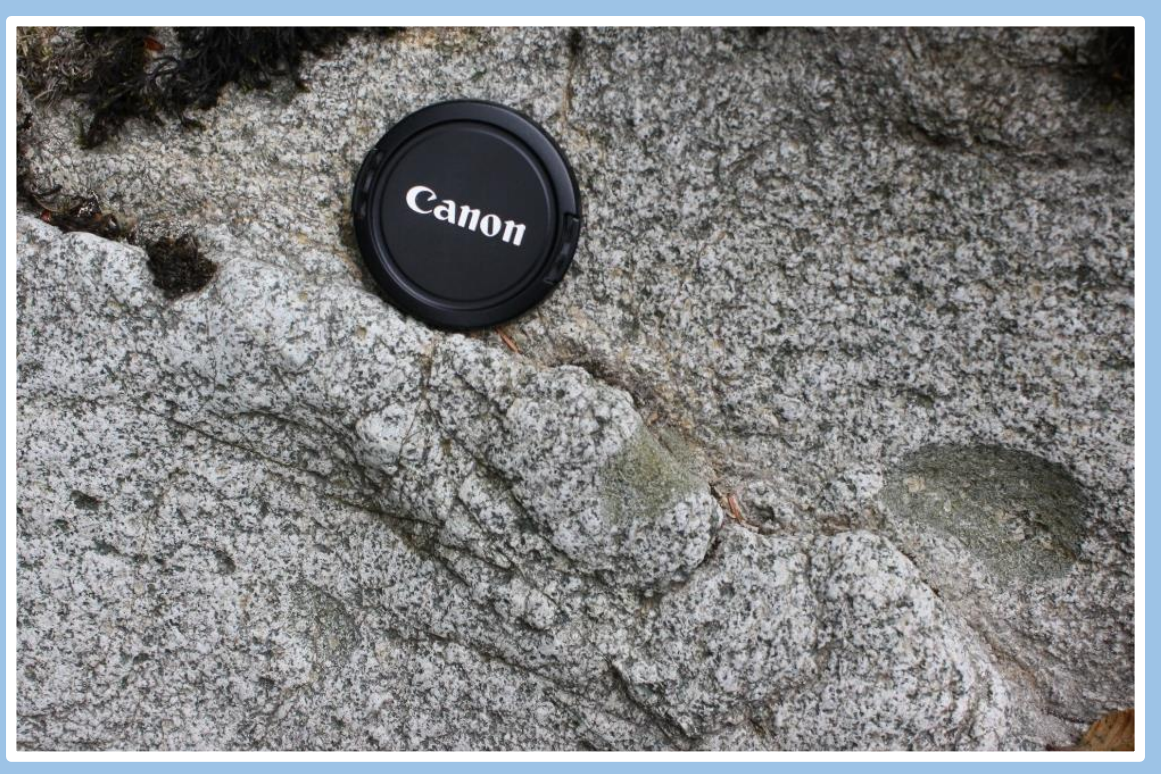

\section{Granite Falls stock:}

Medium-grained, massive, hypidiomorphic hornblende granodiorite. Minor quartz gabbro along the margin.

44-45 Ma based on U-Pb zircon and K-Ar hornblende ages (Yeats and Engels, 1971; M. Eddy, written comm., 2016; Dragovich et al., 2016).

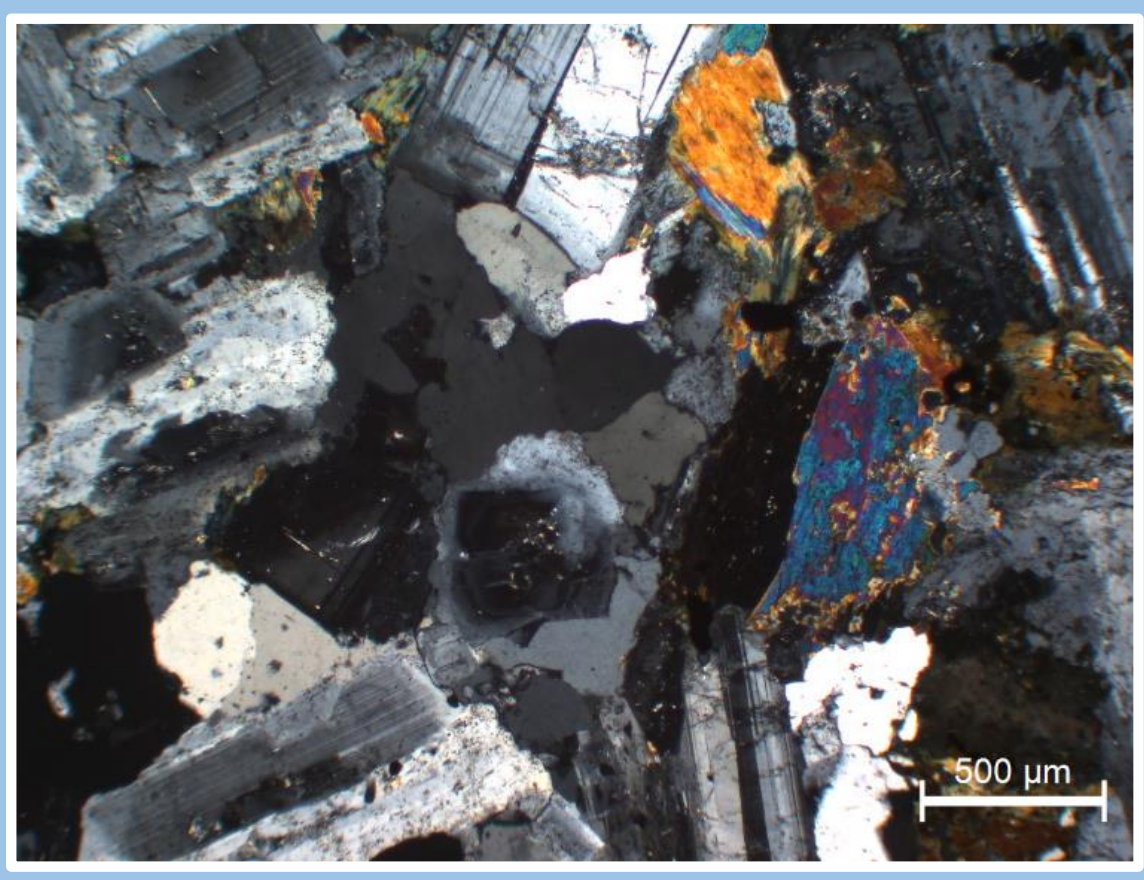

Dragovich et al. (2016) identified a contact complex to the stock with numerous, 1 to 20 meter thick dikes of dacite, rhyolite, and lesser andesite. Some dikes are well preserved while others are cataclastically deformed bodies that have a distinct fracture cleavage. 


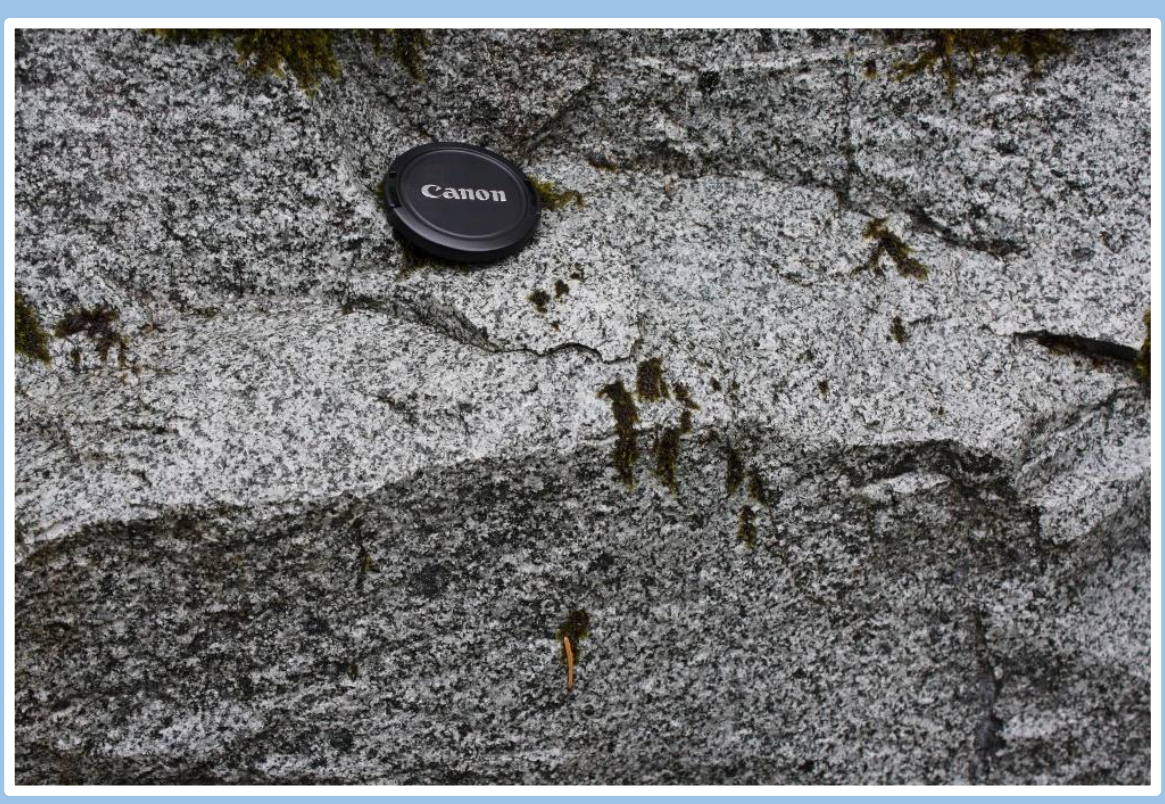

Youngs Creek intrusive complex:

Medium-grained, massive, hornblende granodiorite.

39-43 Ma based on U-Pb zircon ages (Dragovich et al., 2013).

Similar in age to the 36-47 Ma volcanic rocks of Mount Persis.

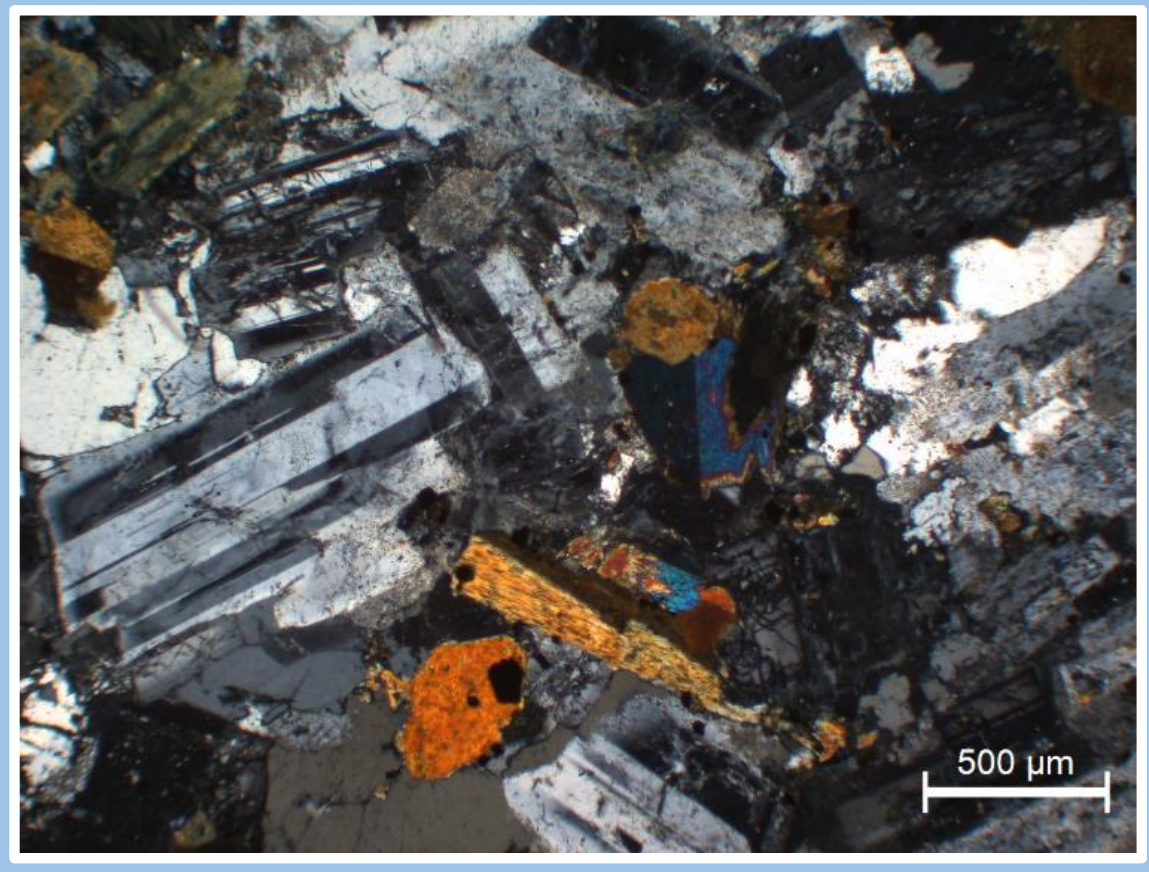

Dragovich et al. (2013) suggested the Youngs Creek intrusive complex was one of a number of intrusive centers for the volcanic rocks of Mount Persis. Others possibly include the $47 \mathrm{Ma}$ Fuller Mountain plug (Tabor et al., 1993) and Drunken Charlie Lake intrusive complex (Dragovich et al., 2013) 

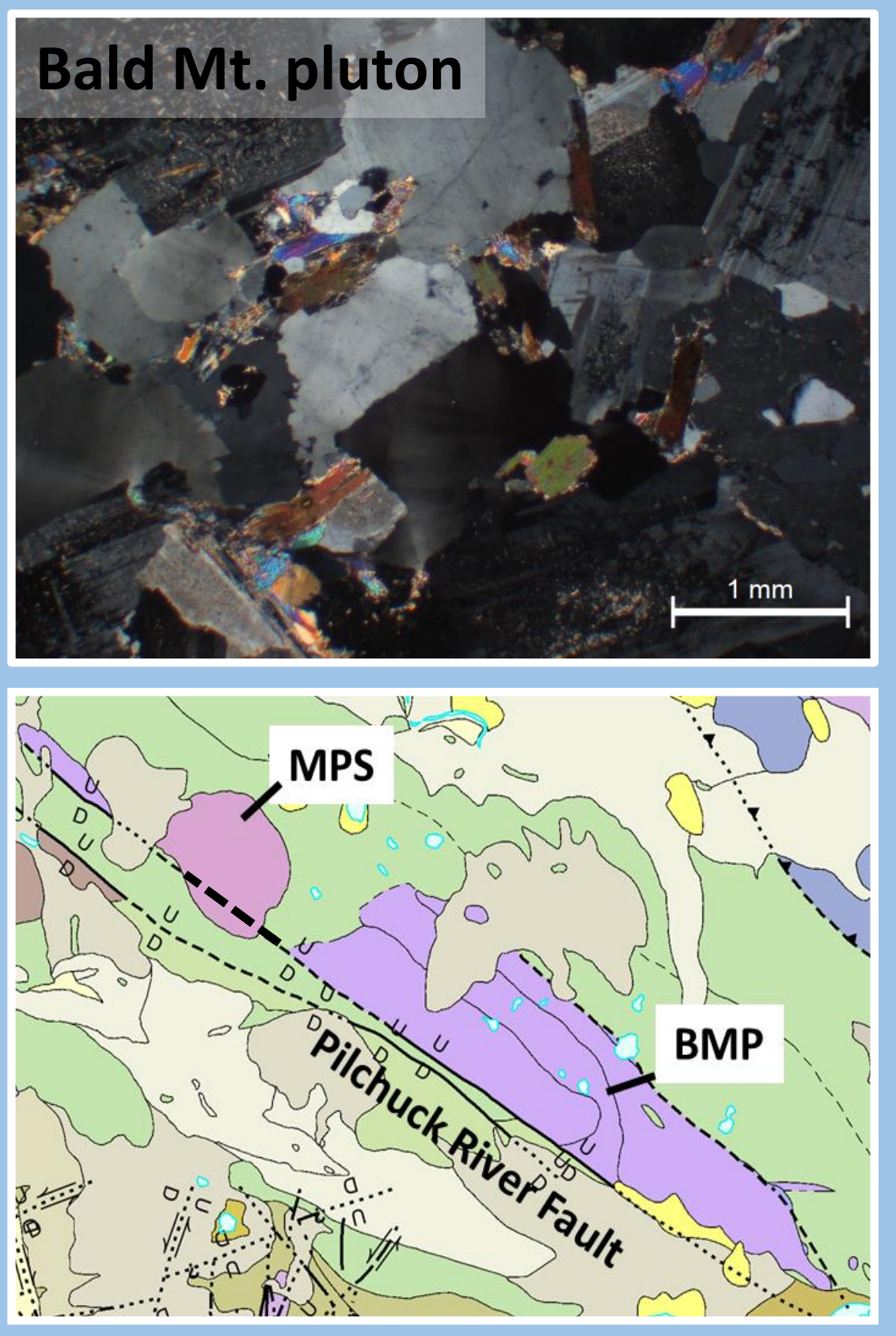

\section{Bald Mountain pluton:}

Medium- to coarse-grained, massive, muscovite biotite granodiorite. Minor quartz gabbro along the margin.

Trace cordierite and garnet occur in the BMP.

Discordant zircon U-Th-Pb ages range between $50-55$ Ma (Tabor et al., 1993)

Tabor et al. $(1993,2002)$ suggest the BMP was strongly recrystallized by the intrusion of the MPS.

Pluton emplacement was largely to completely structurally controlled by bounding faults (Wiebe, 1963). 

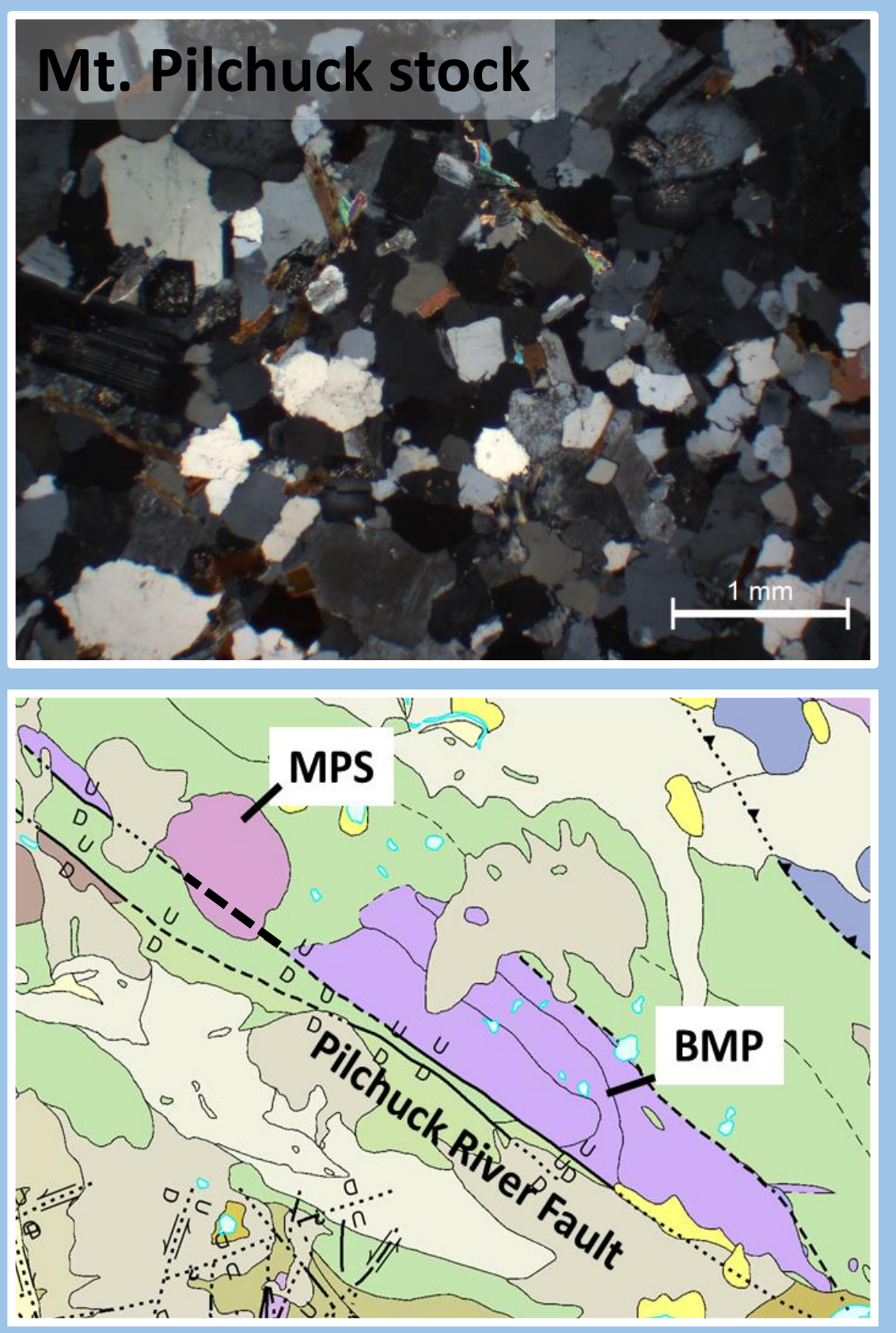

Mount Pilchuck stock:

Medium-grained, massive, muscovite biotite granite.

Trace cordierite and garnet occur in the BMP.

49-50 Ma based on U-Pb zircon and K-Ar hornblende ages (Yeats and Engels, 1971; M. Eddy, written comm., 2016)

Tabor et al. $(1993,2002)$ suggest the BMP contact metamorphism the MPS.

Pluton emplacement was largely to completely structurally controlled by bounding faults (Wiebe, 1963). 

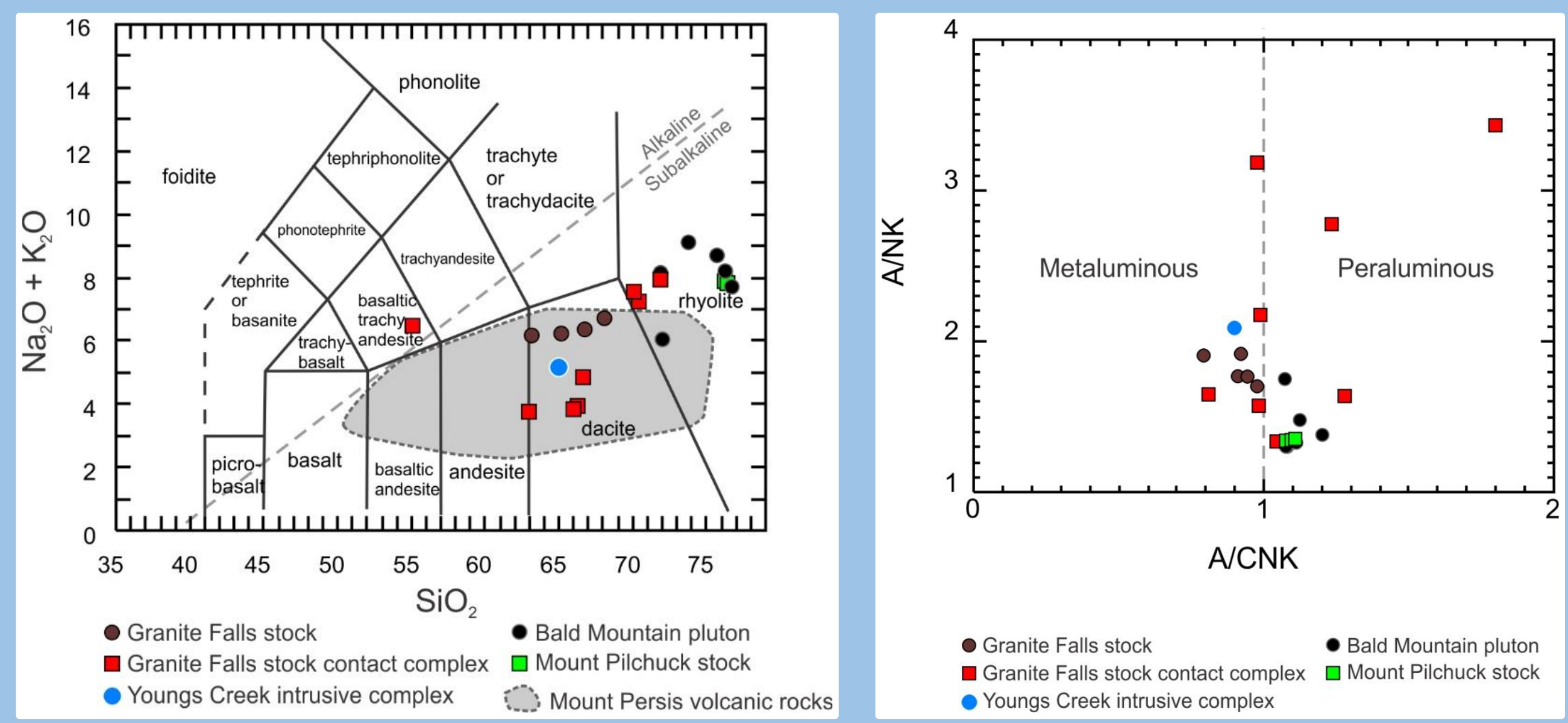

GFS and YCIC metaluminous, medium-K, calc-alkaline affinities. Continental arc setting.

BMP and MPS peraluminous, high-K, calc-alkaline affinities. S-type granites from crustal melts.

(Campbell, 1991; Dragovich et al., 2016) 


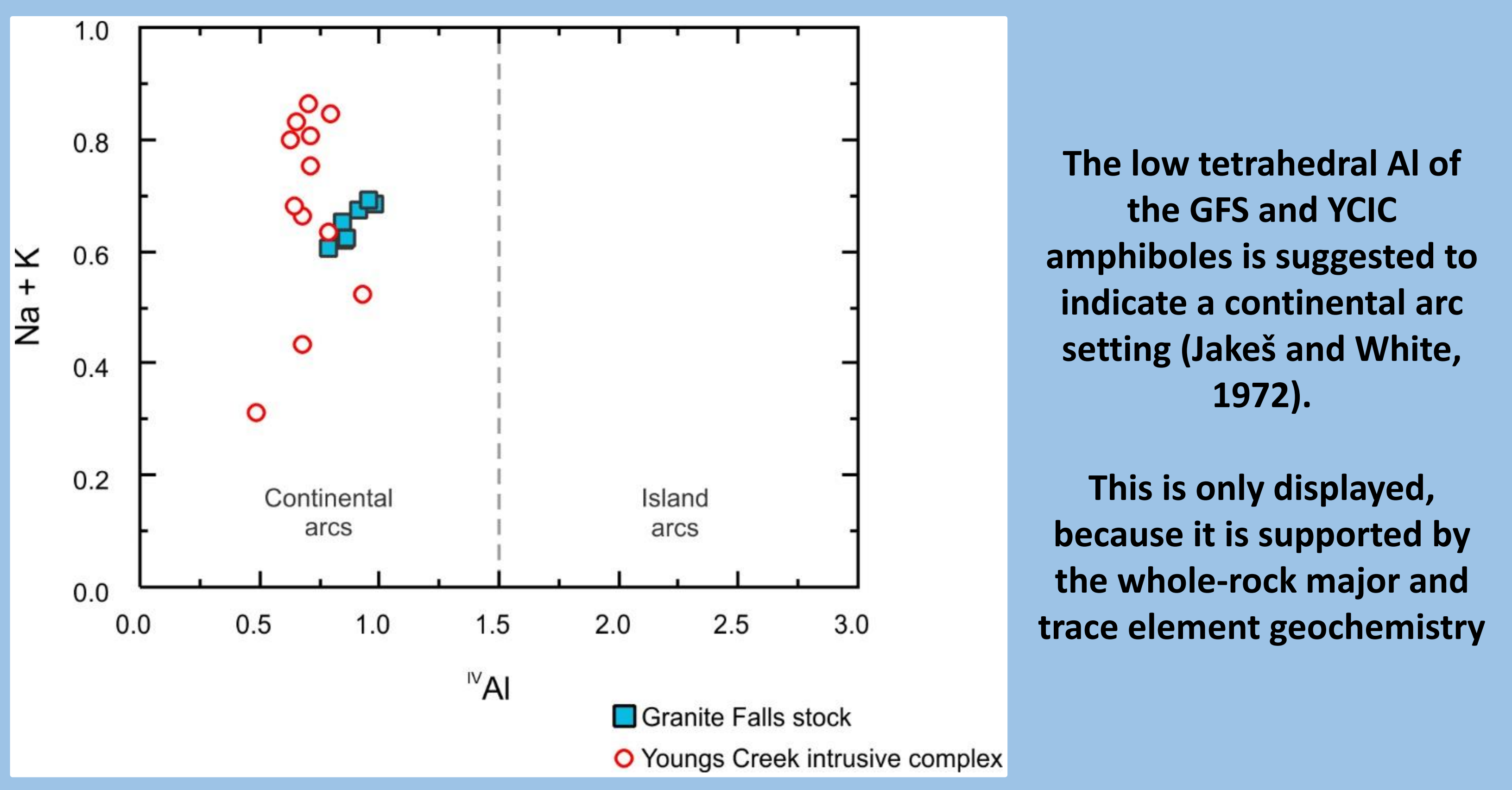



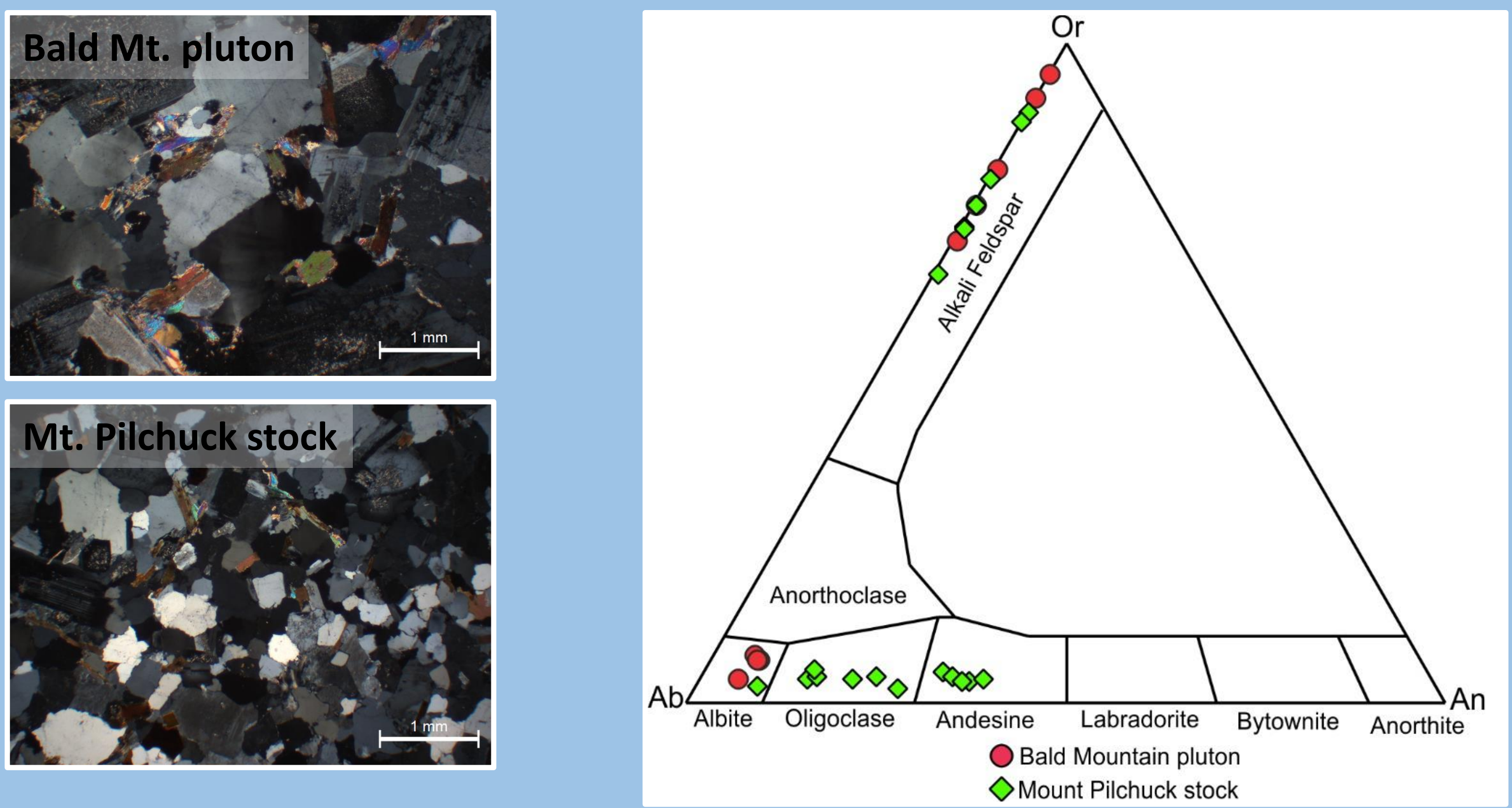

Feldspar compositional classification for the BMP and MPS 

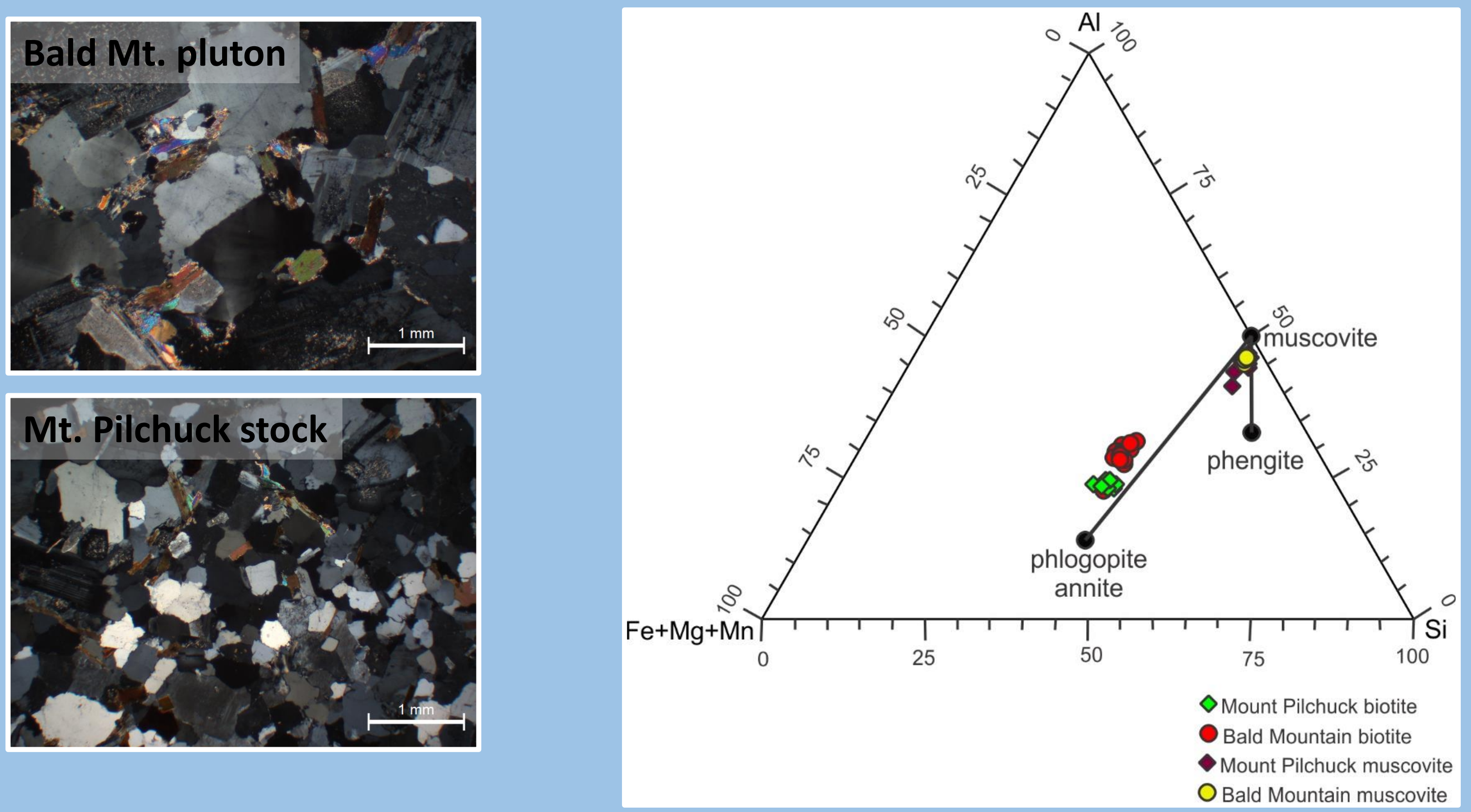

Mica compositional classification for the BMP and MPS. Diagram modified from Speer and Becker (1992) 


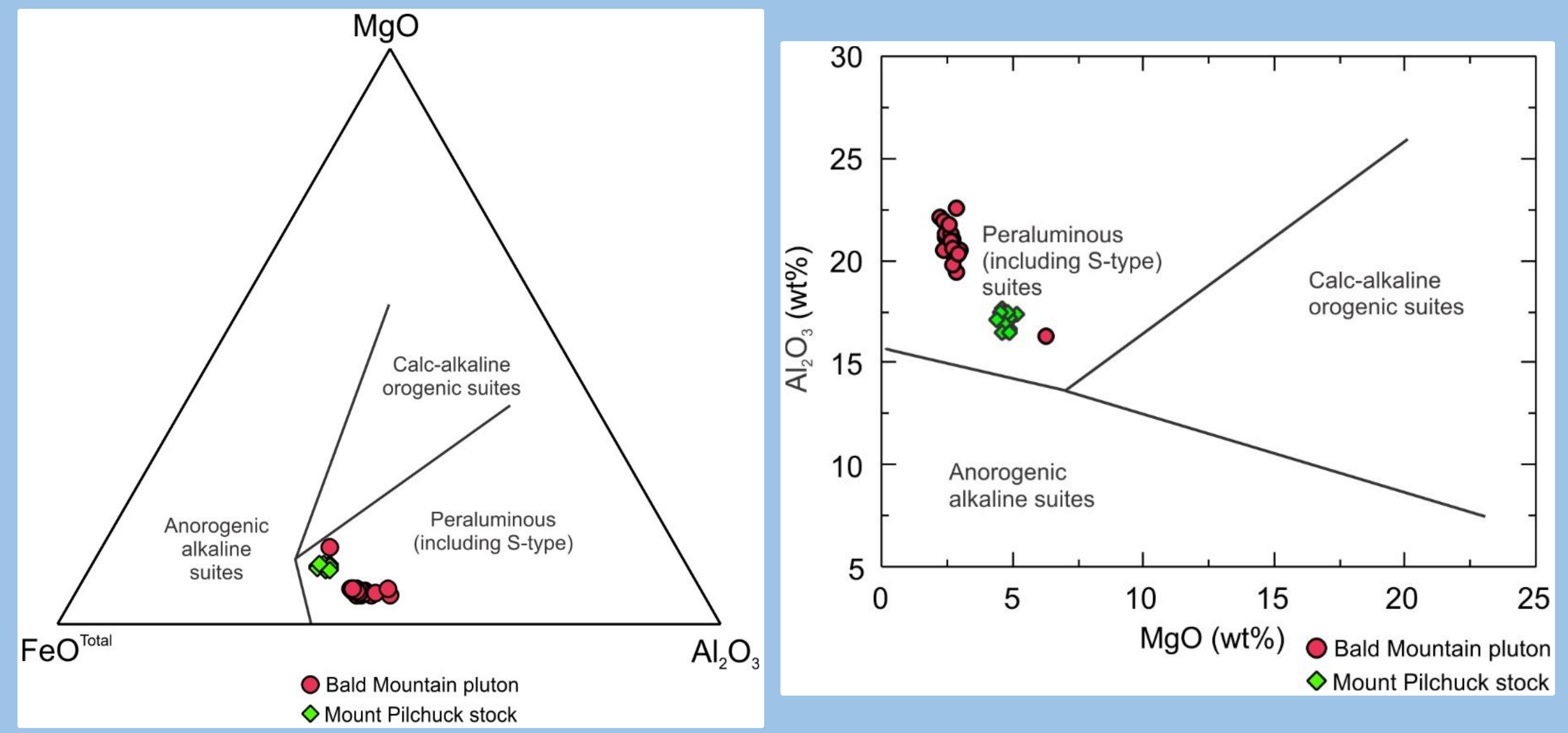

BMP and MPS biotite plotted on discriminant diagrams of Abdel-Rahman (1994). Note the biotite from both stocks reflect the major-element peraluminous affinities. 
Bald Mountain pluton

Mount Pilchuck stock

\section{Granite Falls stock}

\section{Youngs Creek intrusive} complex

* = Biotite thermometer from Luhr et a. (1984)

† = Phengite barometer from Massonne \& Schreyer (1987)

\# = Amphibole thermobarometer from Ridolfi et al. (2010)

‡ = Depth estimated using a barometric gradient of $0.33 \mathrm{kbar} / \mathrm{km}$
$4.5 \pm 0.3^{+}$

13.64

\begin{tabular}{l|l}
$653 \pm 17^{*}$ & $5.4 \pm 0.8^{+}$
\end{tabular}

16.36

$820 \pm 10^{\#}$

$0.69 \pm 0.07^{\#}$

2.09

$814 \pm 45^{\#} \quad 0.57 \pm 0.08^{\#}$

1.73 


\section{Eocene Plutons}

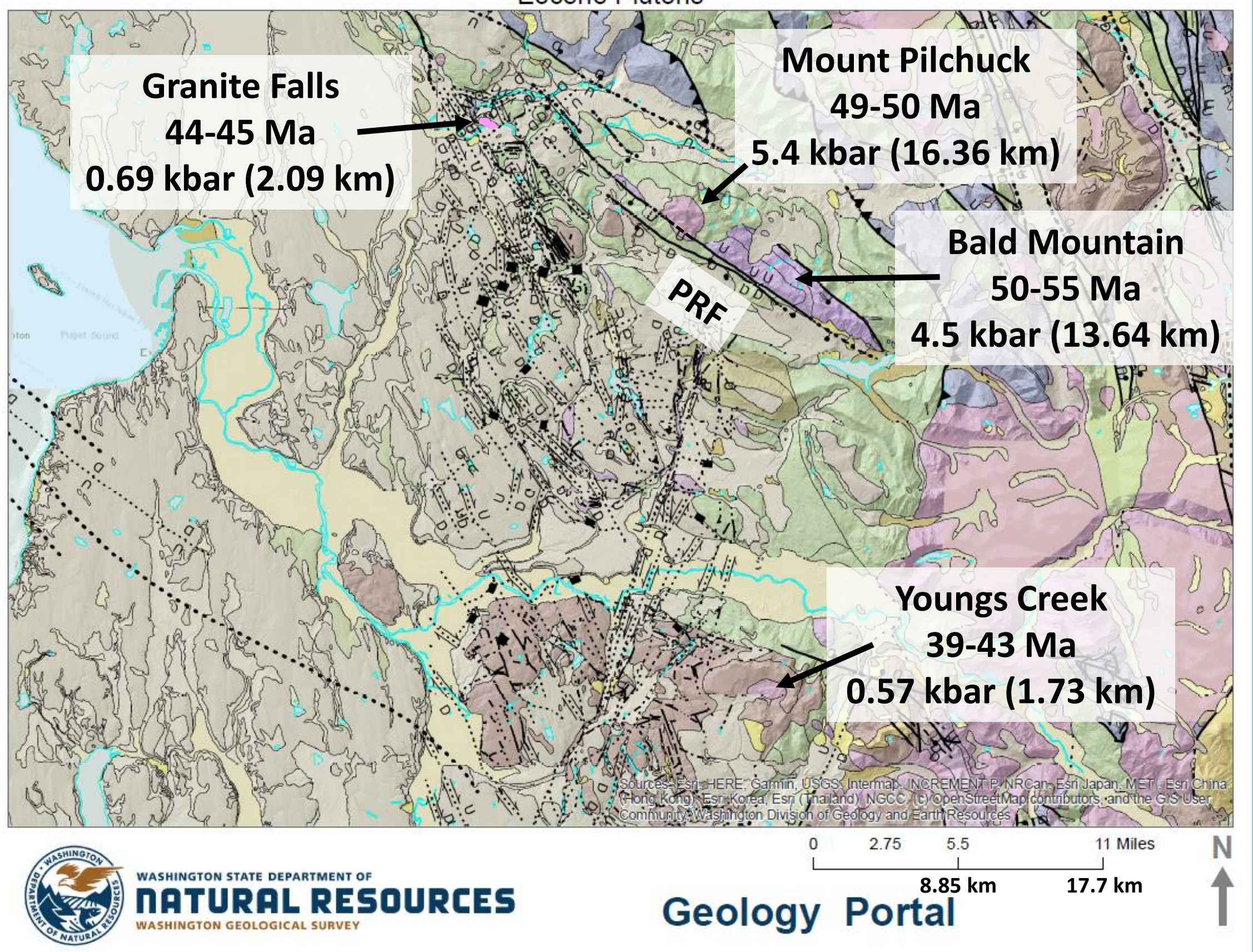

Eocene mineral PT estimates suggest $>12 \mathrm{~km}$ of syn- to post-Eocene displacement on the Pilchuck River Fault (PRF).

The extrusive rocks interpreted to be eruptive products of the BMP and MPS, Hanson Lake rhyolite, was deposited in the transtensional basin to the southwest of these plutons.

This does not account for lateral offset on the PRF. 